Article

\title{
A Prototype of an Electronic Pegboard Test to Measure Hand-Time Dexterity with Impaired Hand Functionality
}

\author{
Bassam Al-Naami $^{1, *(\mathbb{D})}$, Feras Al-Naimat ${ }^{2}\left(\mathbb{D}\right.$, Abdul-Majeed Raja M. Almalty ${ }^{3}$, Paolo Visconti ${ }^{4, *(D)}$ \\ and Abdel-Razzak Al-Hinnawi ${ }^{5}$ (D)
}

1 Department of Biomedical Engineering, Faculty of Engineering, The Hashemite University, Zarqa 13133, Jordan

2 Department of Medical Engineering, Al-Ahliyya Amman University, Amman 19328, Jordan; f.alnaimat@ammanu.edu.jo

3 Physical Therapy Department, College of Allied Health Sciences, The Hashemite University, Zarqa 13133, Jordan; abedmalty@hu.edu.jo

4 Department of Innovation Engineering, University of Salento, 73100 Lecce, Italy

5 Faculty of Allied Medical Sciences, Al-Isra University, Amman 11622, Jordan; abedalrazak.henawai@iu.edu.jo

* Correspondence: b.naami@hu.edu.jo (B.A.-N.); paolo.visconti@unisalento.it (P.V.)

Citation: Al-Naami, B.; Al-Naimat, F; Almalty, A.-M.R.M.; Visconti, P.; Al-Hinnawi, A.-R. A Prototype of an Electronic Pegboard Test to Measure Hand-Time Dexterity with Impaired Hand Functionality. Appl. Syst. Innov. 2022, 5, 2. https://doi.org/10.3390/ asi5010002

Academic Editor: Christos Douligeris

Received: 20 November 2021

Accepted: 18 December 2021

Published: 22 December 2021

Publisher's Note: MDPI stays neutral with regard to jurisdictional claims in published maps and institutional affiliations.

Copyright: (C) 2021 by the authors. Licensee MDPI, Basel, Switzerland. This article is an open access article distributed under the terms and conditions of the Creative Commons Attribution (CC BY) license (https:// creativecommons.org/licenses/by/ $4.0 /$ )

\begin{abstract}
This paper proposes an electronic prototype of the Grooved Pegboard Test (GPT), which is normally used to test the presence of hand dexterity. The prototype imitates the geometrical dimensions of an on-the-market GPT device, but it is electronic, not manual like the one available now for users. The suggested electronic GPT device makes automated time calculation between placing the first and the last peg in their designated locations, instead of manually observing a stopwatch normally used during the GPT. The electronic GPT prototype consists of a fabricated wooden box, electronics (switches and microcontroller), and liquid crystal display (LCD). A set of 40 normal volunteers, 20 females and 20 males, tested the designed prototype. A set of six volunteers with chronic medical conditions also participated in evaluating the proposed model. The results on normal volunteers showed that the proposed electronic GPT device yielded time calculations that match the population mean value of similar calculations by the GPT device. The one-sample $t$-test showed no significant difference in calculations between the new electronic GPT and the manual GPT device. The $p$-value was much higher than 0.05 , indicating the possible use of the suggested electronic GPT device.
\end{abstract}

Keywords: assistive medical equipment; grooved pegboard test; hand dexterity; physiotherapy

\section{Introduction}

There are many validated tests to measure hand dexterity for patients with impaired hand function. Among them, there are the Grooved Pegboard Test (GPT), Purdue Pegboard Test (PPT), and Nine Holes Peg Test (NHPT) that were manufactured by Lafayette Instrument Company [1]. Each testing tool has a board with holes on it, a pegs tray, and a certain number of pegs. The common idea of these tests is placing a certain number of pegs in a set of holes, which are arranged differently on a board, as fast as a tested person can. The hands' dexterity is assessed by recording the reaction time in placing pegs on the holes at the pegs board.

The GPT has been used previously in diagnosing many diseases [2-12]. For example, Amirjani et al. used the GPT to assess the carpal tunnel syndromes. They compared 190 carpal tunnel patients with 122 healthy people, claiming that the GPT exhibits high reliability in observing and assessing carpal tunnel syndromes [2]. In an early study in 1995, a set of normal elderly people from 60 to 89 years old participated in evaluating the GPT, yielding high reliability in monitoring the hands' dexterity for normal elderly people [3]. Moreover, there were several studies to assess the handgrip strength for patients with hyperthyroidism [4,5]. In addition, the GPT was used with patients suffering from the 
neurocognitive and fine motor deficit in asymptomatic adolescents during the subacute period after concussion [6,7]. The Grooved Pegboard Test was also used to assess the fine dexterity after virtual reality (VR) immersion and cyber-sickness for 89 participants aged between 19 and 36 years [8]. In addition, the GPT was used to assess the hand dexterity for various diseases [9-12].

Although the FPT, PPT, and NHPT all have the same testing principle in examining hand dexterity, they differ in the number and the arrangement of the board configuration, as shown in Figure 1. They also proved to be efficient in different diseases. The GPT has 25 holes, which are arranged as five rows by five columns, and has been used for the post-brain surgery and for the possibility of assessing the lateral brain damage [13-15]. The study by Ying-Chih et al. has shown that the GPT is not efficient when used with very young or very old adults and with patients in the early stage of neurological diseases [16]. In contrast, the PPT has two sets of 25 holes arranged as right and left columns. The PPT has been used extensively to aid in the selection of employees for jobs that require fine motor dexterity and coordination, such as assembly work settings and industrial factories. Further, this test has been used with patients affected by the Parkinson, Multiple Sclerosis, Stroke, and other patients with neurological diseases $[17,18]$. It has been used in the rehabilitation for evaluating the progress and/or degree of the disability documentation $[19,20]$. Finally, the NHPT is designed with three rows and three columns of holes (nine holes). It has the benefit of being a shorter version and easier than the GPT and PPT. The NHPT has been used with adult cases with severe and complicated neurological conditions such as the Parkinson's disease and Multiple Sclerosis [21-23]. Figure 1 demonstrates samples of the GPT, PPT, and NHPT boards.

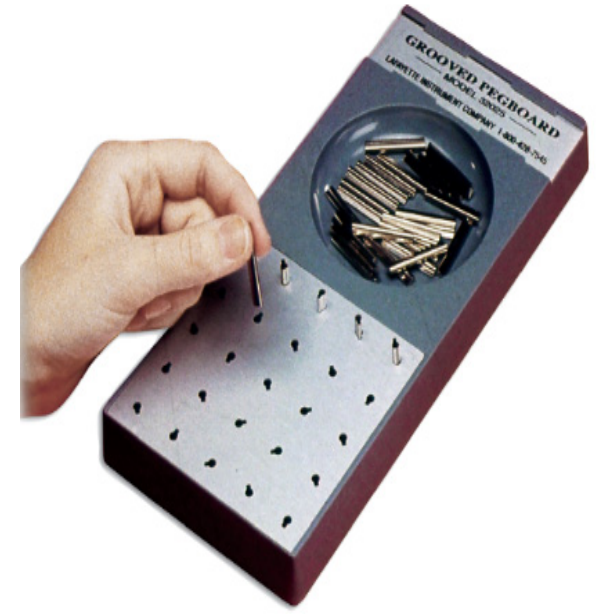

(a)

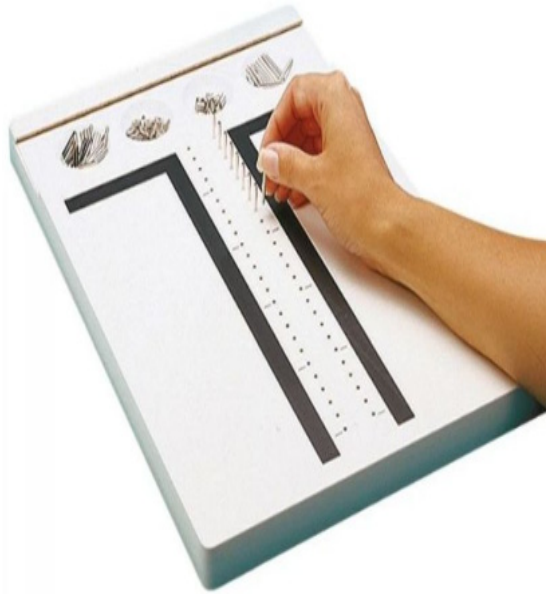

(b)

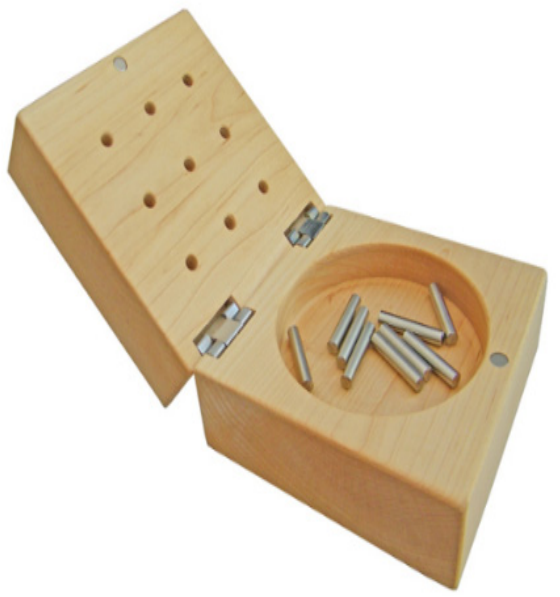

(c)

Figure 1. Three examples of different types of Pegboard Tests: (a) Grooved Pegboard Test (GPT), (b) Purdue Pegboard Test (PPT), and (c) Nine Holes Peg Test (NHPT).

The GPT is a rectangle board with a tray for the 25 pegs and a stopwatch to calculate the time for placing the pegs in the holes $[19,24-26]$. The stopwatch starts once a tested person has picked the first peg and ends with placing the last peg in the hole, then performance time is calculated. However, the manual time calculation might be vulnerable to human errors when switching the stopwatch on and off. The test needs to be held and supervised by a therapist.

The aim of this study is to build a prototype of an automated GPT device to calculate the precise performance time and omit any lost time due to human errors. The system is easy to use at home without the supervision of a therapist. This would enable the patients, by themselves, to observe their progression from treatment or their compliance to the home program treatment. The system has an LCD screen reading the elapsed performance time. It mimics the GPT device's configuration in which it has similar dimensions to the 
tray, pegs, and holes. Therefore, the usage of the suggested electronic Pegboard Test (PT) device has been compared against the GPT device. A pilot study was conducted, and the one-sample t-test was calculated, comparing the mean of the measurements from the electronic GPT prototype with the population mean value of measurements from GPT devices. To the best of our knowledge, this is the first pilot study to design an electric and automated GPT; there are no similar experiments in the literature.

This research work is structured as follows: Section 2 describes the materials and method, including the geometrical design of the wooden board, electronic circuits, microcontroller (i.e., Arduino MEGA acquisition and processing board), and the display unit (Liquid Crystal Display, LCD). Section 3 demonstrates the results obtained from testing the proposed electronic GPT system. The statistical analysis of the results is presented in Section 4 , as well as the benefits and the performance stability of the proposed device.

\section{Materials and Methods}

\subsection{Pegboard Construction}

The suggested prototype of the GPT device consisted of a wooden board with an aluminum sheet and an electrical circuit, which was composed of a microcontroller and a liquid crystal display (LCD). The prototype imitates the GP's geometrical architecture in which it has a tray of holes and a peg container. Figure 2 illustrates an image of the suggested prototype (a) and its architecture geometry (b).

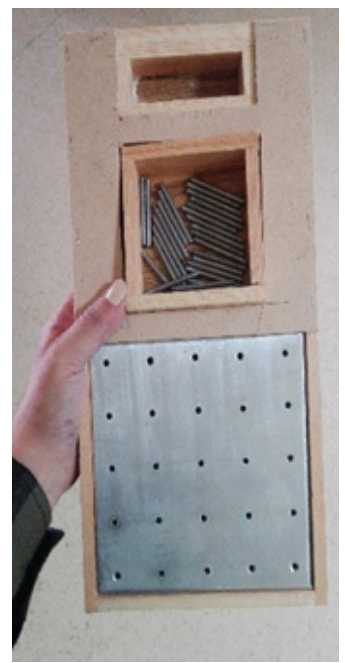

(a)

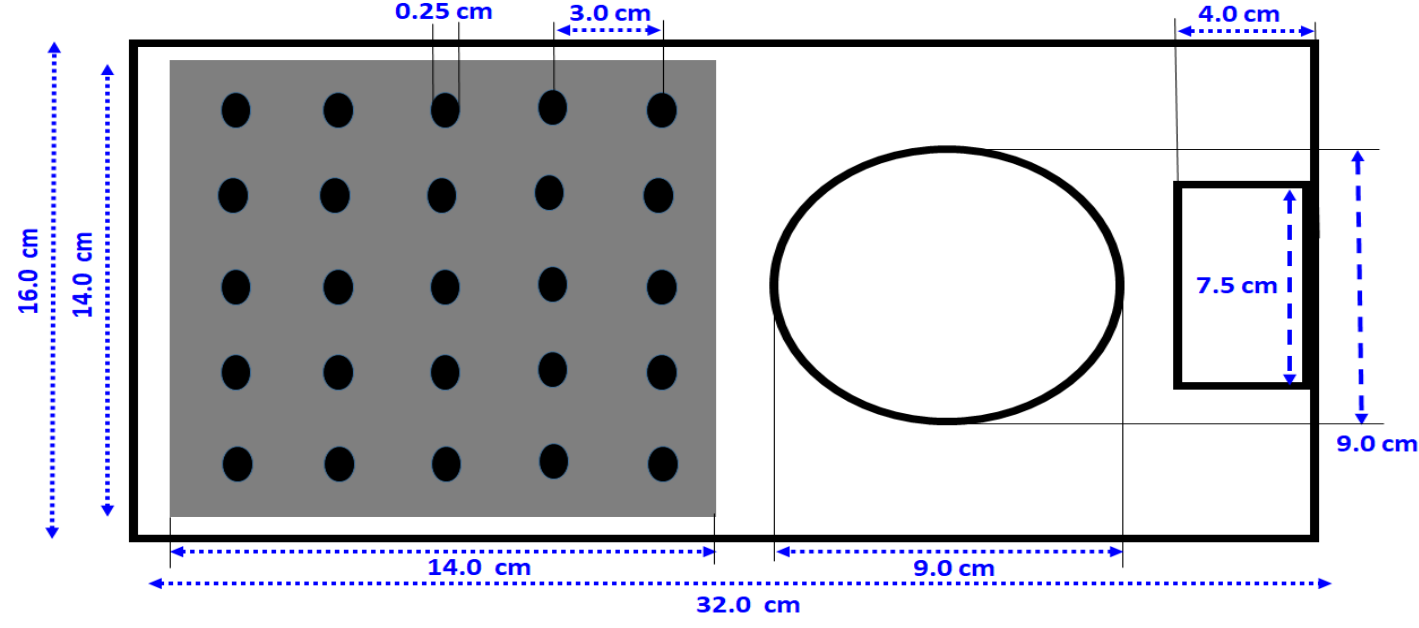

(b)

Figure 2. The image (a) is the external look of the proposed pegboard and its geometrical dimensions (b).

\subsection{The GPT Board}

It is made from wood and an aluminum sheet. The wooden board was constructed at the cast carpentry workshop. Its length, width, and height were erected to 32,16 , and $4.5 \mathrm{~cm}$, respectively. These dimensions are similar to standard GPT devices [13]. Then, an aluminum sheet was cut to a 14 by $14 \mathrm{~cm}$ square aluminum sheet at a cast iron workshop. The sheet was dotted to design a pattern of 25 holes with a $3 \mathrm{~cm}$ distance between every two adjacent holes. Finally, the sheet was drilled at the designated dotted points. The diameter of each hole was $0.25 \mathrm{~cm}$, after which the sheet was fixed at the top of the wooden peg tray, as shown in Figure 2.

\subsection{Electric Circuit}

The electric circuit consisted of a microcontroller (i.e., Arduino MEGA) and a liquid crystal display (LCD), as shown in Figure 3. The Arduino MEGA is a single-board microcontroller with 54 input/output pins. It has its own programming language (i.e., Arduino 
software), permitting the design of electronic projects and systems for various applications. It is equipped with a USB cable port to transfer code from the computer to the board. The detailed structure and specifications can be found in ref. [27]. A matrix of 25 switches is mounted under the aluminum sheet, so there is an electronic switch under each hole. The experiment employed the Stainless-Steel Capacitive Switches type CPS16B (Langir Electric Co., Zhejiang, China). Each switch is $16 \mathrm{~mm}$ in size and requires a $5 \mathrm{~V}$ DC power supply. The microcontroller, which can be mounted under the aluminum sheet, receives an input pulse signal from each switch via an electric wire. Thus, there are 25 wires, one wire under each hole. Once the participant places the peg in the correct hole, the electronic switch becomes "closed" generating a pulse signal sent to the Arduino board. The microcontroller was programmed to calculate the elapsed time between the first and last peg. The result was displayed on the LCD screen. The power supply was drawn from a computer laptop. Figure 3 shows images of the electric circuit and the circuit block diagram.

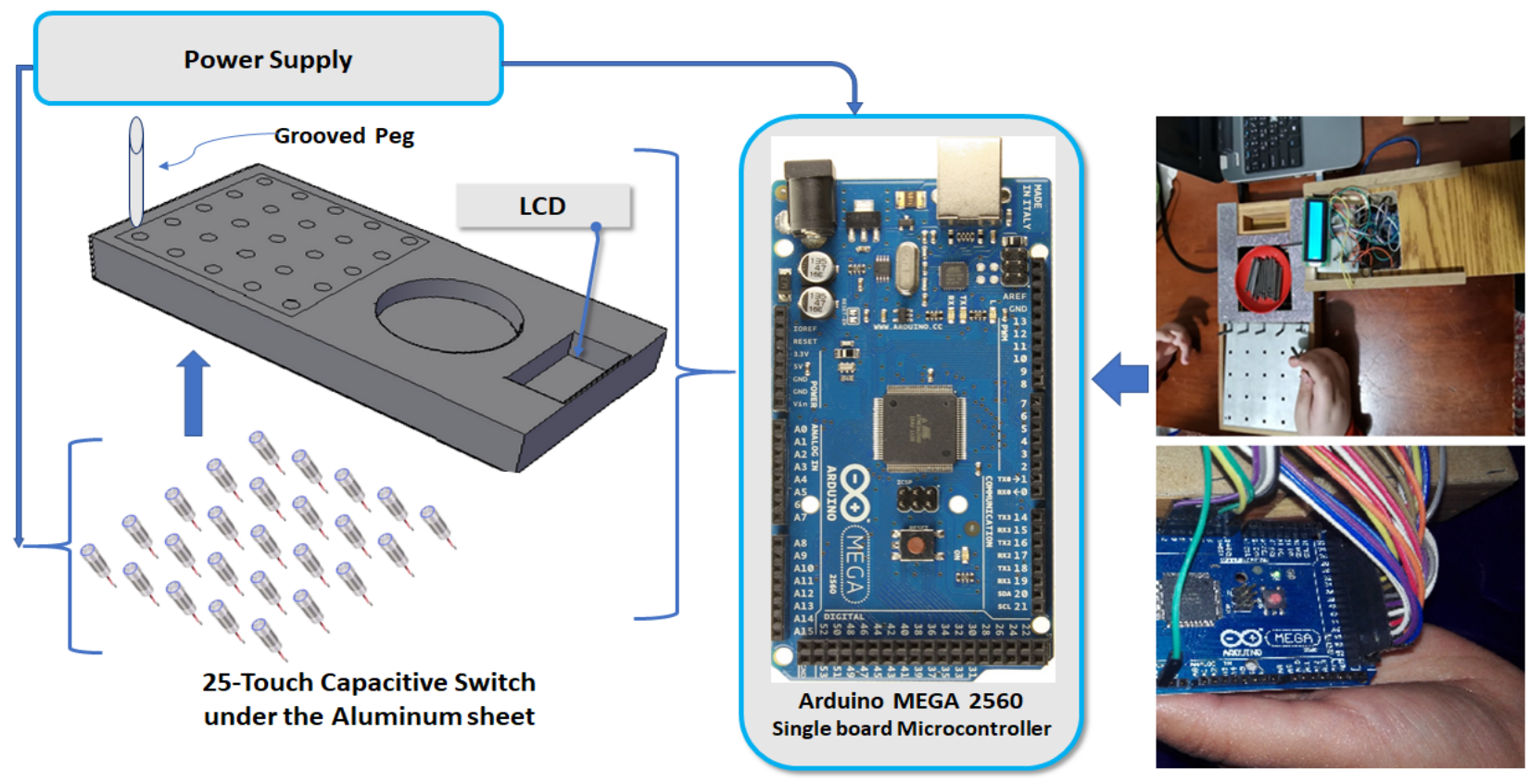

Figure 3. Images of the experimental electric circuit.

\subsection{Participants}

Forty normal participants were asked to test the prototype, 20 women and 20 men. They are all between 20 and 29 years old. Six people with medical conditions were also included in this study, four patients with neurological disorders, and two with bone accidents. Table 1 illustrates the distribution of all the participants; all of them, the normal and abnormal people, were asked to sign a consent before testing the designed system in order to meet the research ethics (i.e., all aspects of the experiment were explained, including the test description, equipment, and any risks). The Institutional Review Board (IRB) approved the experiment; the IRB number is reported in the Institutional Review Board Statement section at the end of the manuscript.

Table 1. The participants' distribution.

\begin{tabular}{cccc}
\hline & Normal Participants & \multicolumn{2}{c}{ Abnormal Participants } \\
\hline Pathology & Normal & Neurology Disorders & Bone accidents \\
Women & 20 & 2 & 1 \\
Men & 20 & 2 & 1 \\
Total & 40 & 4 & 2 \\
\hline
\end{tabular}




\subsection{Procedures}

Each participant was asked to place the pegs in their designated places using the dominant hand. Then, the participants were asked to repeat the test but using the nondominant hand. For each run, the participant placed the 25 pegs in their correct designated holes in sequential order. The first peg should be placed in the first left hole in the first row of holes, while the last peg should be placed in the last right hole in the fifth row of holes (Figure 2). In contrast, for the non-dominant hand, the first peg should be placed in the first right hole in the first holes' line while the last peg should be placed in the left hole in the last holes' line. The microcontroller calculated the elapsed time between putting the first and last peg and then displayed it on the LCD.

\section{Results}

Table 2 illustrates the average (AVG) and the standard deviation (STDev) in the recorded time (i.e., measurements) of the dominant and non-dominant hands of female, male, and all participants. On the other hand, to assess the validation of the prototype, the measurements were compared with the population mean values (i.e., reference values for normal people) stipulated by the manufacturer of the manual GPT device [1,2], which are reported in Appendix A. This value was evaluated by calculating the one-sample $t$-test, which assesses the significant difference ( $p$-value) between the mean of the measurements and the population mean value (i.e., the hypothesized value). The null hypothesis was set that the mean of measurements from the two different GPT devices is different. The resultant $p$-values are listed in Table 2. It also lists the AVG and the STDev of the population records, which is the AVG and STDev of time to finish the test by normal people whose age is in the range 20-29 years old.

Table 2. The AVG and STDev of measurements of time on Normal Participants aged 20-29 years old.

\begin{tabular}{|c|c|c|c|c|}
\hline & \multicolumn{2}{|c|}{ Dominant Hands (s) } & \multicolumn{2}{|c|}{ Non Dominant Hands (s) } \\
\hline & AVG & STDev & AVG & STDev \\
\hline Women (No. 20 participants) & 63.2 & 7.6 & 69.8 & 8.7 \\
\hline Men (No. 20 participants) & 64.0 & 10.5 & 70.1 & 12.4 \\
\hline Total (No. 40 Participants) & 63.6 & 9.1 & 69.9 & 10.6 \\
\hline Population Mean Value [2] & 63.4 & 7.9 & 69.05 & 18.7 \\
\hline$p$-value (Women) & \multicolumn{2}{|c|}{0.91} & \multicolumn{2}{|c|}{0.72} \\
\hline$p$-value (Men) & \multicolumn{2}{|c|}{0.82} & \multicolumn{2}{|c|}{0.74} \\
\hline$p$-value (Women + Men) & \multicolumn{2}{|c|}{0.90} & \multicolumn{2}{|c|}{0.62} \\
\hline
\end{tabular}

In addition, for further demonstration of the results, Figures 4 and 5 demonstrate the box plots of all measurements on the dominant and non-dominant hands from females, males, and all participants. These figures allowed us to see the distribution of calculations from all volunteers who underwent the new electronic GPT, with reference to the AVG \pm STDev of the population mean of records from GPT devices.

On the flip side, the six participants with medical conditions underwent the same test. They were from a different range of age groups. Table 3 shows the measurements on the right and left hands for each separate case. For comparison, it also illustrates the limits of the population mean (i.e., Maximum and Minimum) of the required time to finish the test by normal people of different ages (as reported in ref. [13], specifically in the table related to the reference-population mean values of time measurements on healthy people undergo manual GPT devices). Exceeding these limits indicates the presence of a hand dexterity. 


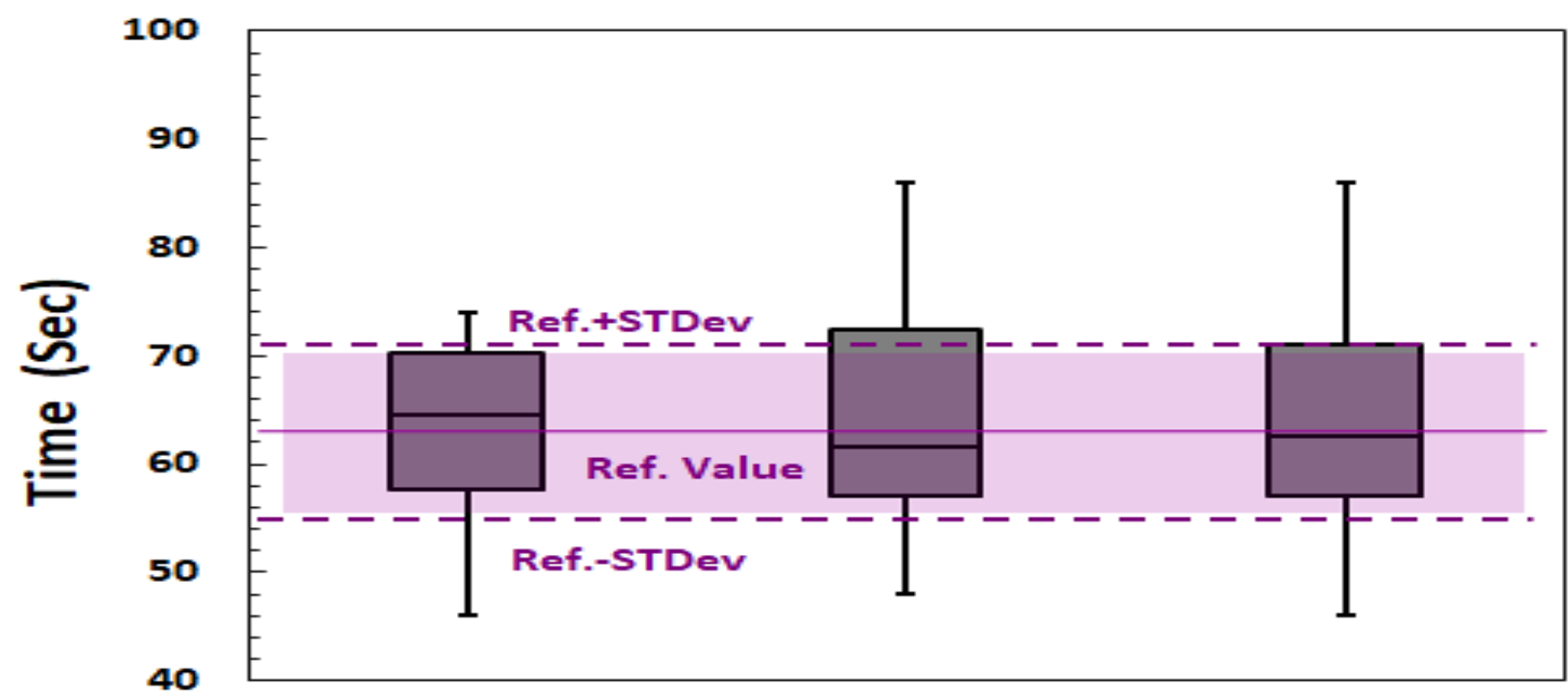

Female

Male

Male + Female

Figure 4. Box plot of measurements related to the dominant hands.

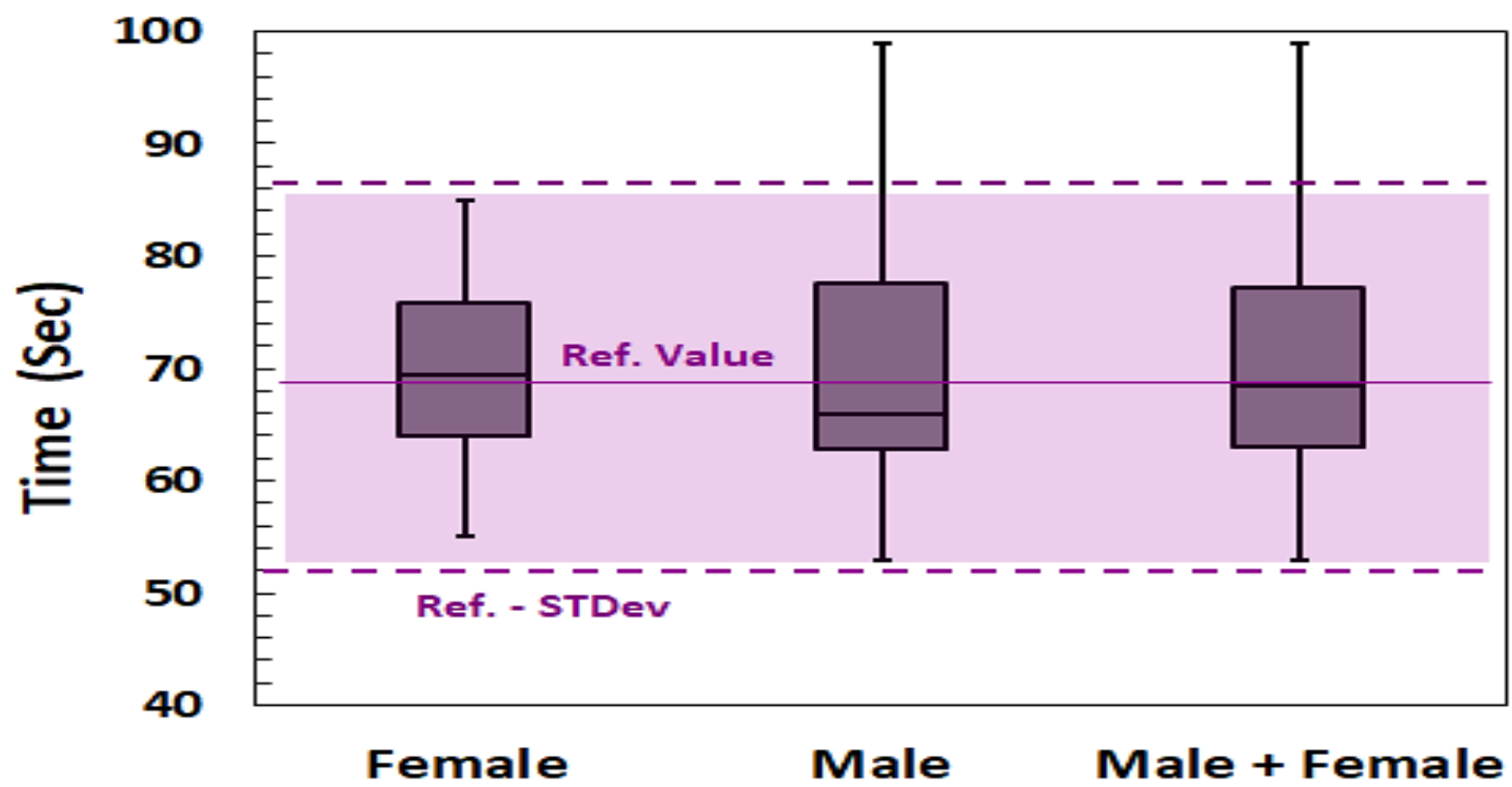

Figure 5. Box plot of measurements related to the non-dominant hands.

Table 3. The measurements of time on right and left hands for some people with medical conditions.

\begin{tabular}{ccc}
\hline Medical Condition & Right Hand (s) & Left Hand (s) \\
\hline Ataxia (in right hand) & 441 & 165 \\
Autism & 586 & 333 \\
Cerebrovascular accident (CVA) (Stroke in right hand) & 171 & 96 \\
Cerebral Palsy (CP) (in Right hand) & 567 & 421 \\
Patient no. 1: Bone Fracture (in left Hand) & 99 & 109 \\
Patient no. 2: Bone Fracture (in left Hand) & 85 & 184 \\
Limits of Population Mean Values from GPT devices [2] & Dominant Hand: 60.96-82.7 s \\
& Non-dominant hand: 65.61-87.95 s \\
\hline
\end{tabular}




\section{Discussion}

Table 2 shows the experimental results on 40 normal people who are 20-29 years old. The AVG \pm STD of measurements from dominant hands was $63.2 \pm 7.6,64.0 \pm 10.5$, and $63.6 \pm 9.1$ for female, male, and all participants, respectively. These values approached the population AVG and STDev values, which are $63.4 \pm 7.9 \mathrm{~s}$ (Appendix A) in reference [13]. Similarly, the AVG \pm STDev values of the measurements from non-dominant hands also come close to those of the population values. Therefore, the measurements on dominant and non-dominant hands comply with the population mean value that is reported from the manual GPT device [13].

On the other hand, in Table 2, the $p$-value of the significant difference between the measurements mean and the population mean on dominant hands was $0.91,0.82$, and 0.90 , while it was $0.72,0.74$, and 0.62 for non-dominant hands of female, male, and all participants, in order. All these values reject the hypothesis that there could be a significant difference between calculations from the proposed electronic GPT device (Figures 2 and 3) and the commercially accepted manual GPT device (Figure 1). Therefore, the pilot results in Table 2 rationalize the statement that "the proposed electronic GPT model is technically correct".

Figures 4 and 5 sustain the preceding discussion and findings. They showed that measurements from the suggested electronic GPT were within the zone of AVG \pm STDev interval of the population's calculations by the manual GPT device.

On the other hand, Table 3 illustrates the obtained results related to measurement tests on some volunteers suffering from neurology disorders such as Ataxia, Autism, Stroke, or Cerebral Palsy. The table also demonstrates calculations on volunteers suffering from bone accidents. For both types of disorders (i.e., nerve or bone accidents), the calculations were outside the population mean value limits of normal people (i.e., reference values from GPT devices in Appendix A), indicating the presence of hand dexterity [13]. The clinical analysis of each situation is beyond the scope of this paper. These results, however, could rationalize another proof about the feasibility of the usage of the suggested electronic GPT prototype by patients.

There are two prospective advantages of the suggested electronic GPT. First, the device can be used at home without the supervision of a physiotherapist, allowing patients, by themselves, to observe their medical situations, such as the progression from treatment. The therapists normally use a stopwatch so discomfort or mistakes may occur, which leads to repeat the test. Therefore, the second advantage is the possibility to use the electronic GPT at physiotherapy clinics, minimizing discomfort to both the patient and the therapist [28]. Finally, it may be of importance to note that the prototype can be similarly designed as the PPT or NHPT devices' configuration in Figure 1.

However, the encouraging results in Tables 2 and 3 were only from the pilot study. Therefore, they need to be verified on a large number of volunteers, which is not easily available, to include different groups of ages and different medical conditions. In addition, the matter of importance would be the price effectiveness of the suggested electronic GPT. The predictable cost includes the prices of the microcontroller, electronic switches, and the fabrication of the wooden box.

Unfortunately, no similar studies were reported in the literature to compare with the results in this paper, to the best of our knowledge.

\section{Conclusions}

An electronic GPT prototype was designed and preliminarily tested on 46 volunteers (pilot study). The prototype was equipped with electronic switches, microcontroller, LCD, and wooden box, and was fabricated to match the dimensions of the manual GPT device. The results approached the population mean of calculations by the company's device. They showed no significant difference between calculations by the suggested model and the GPT device. However, in some circumstances related to Epileptic and motor-sensory dysfunction, the new model of the GPT may use as an assistive evaluation $[29,30]$. 
Author Contributions: Conceptualization, B.A.-N. and A.-M.R.M.A.; methodology, B.A.-N., A.-R.A.H., P.V. and A.-M.R.M.A.; software, B.A.-N.; validation, B.A.-N., A.-R.A.-H., P.V. and A.-M.R.M.A.; formal analysis, B.A.-N., F.A.-N., A.-R.A.-H. and A.-M.R.M.A.; investigation, B.A.-N.; resources, B.A.-N. and P.V.; data curation, B.A.-N., F.A.-N., A.-R.A.-H. and A.-M.R.M.A.; writing-original draft preparation, B.A.-N., A.-R.A.-H., P.V. and A.-M.R.M.A.; writing-review and editing, B.A.-N., F.A.-N., A.-R.A.-H., A.-M.R.M.A. and P.V.; visualization, B.A.-N. and A.-R.A.-H.; supervision, B.A.-N. and P.V.; project administration, B.A.-N.; funding acquisition, B.A.-N., F.A.-N. and P.V. All authors have read and agreed to the published version of the manuscript.

Funding: This research did not receive any financial support.

Institutional Review Board Statement: The Institutional Review Board (IRB), faculty of Medicine, Hashemite University approved this study (IRB No. 19013/37). The study was performed in accordance with the revised Declaration of Helsinki 2000 and the National Institutes of Health procedure for healthy volunteers study.

Informed Consent Statement: All experimental procedures and methods were explained to each subject, who then signed the Informed Consent Document approved by the Hashemite University IRB board.

Data Availability Statement: Data of our study are available upon request.

Acknowledgments: We thank Al-Shaikh M., Al-Nsoor S., Al-Khlaifat M., Al-Khalaila B., and AlZoubi I. and other students of biomedical engineering department for efforts in participating in data collection. We thank the medical staff of Physical Therapy division at Prince Faisal Bin Al Hussein Hospital, Zarqa, Jordan, for the support in the conduction of this study.

Conflicts of Interest: The authors declare no conflict of interest.

\section{Appendix A}

The population mean values (i.e., reference values for normal people) were postulated by the booklet for manual GPT devices [1,13]. Table A1 reflect the definitions and the abbreviations stand for in this paper.

Table A1. Definitions and the abbreviations stand for.

\begin{tabular}{cc}
\hline Definition & Abbreviation \\
\hline Grooved Pegboard Test & GPT \\
Liquid Crystal Display & LCD \\
Purdue Pegboard Test & PPT \\
Nine Holes Peg Test & NHPT \\
Institutional Review Board & IRB \\
Average & AVG \\
Standard Deviation & STDev \\
Cerebro-Vascular Accident & CVA \\
Cerebral Palsy & CP \\
Reference & Ref.
\end{tabular}

\section{References}

1. Lafayette Human Evaluation-Instruments. Available online: https:// lafayetteevaluation.com/ (accessed on 7 June 2021).

2. Amirjani, N.; Ashworth, N.L.; Olson, J.L.; Morhart, M.; Chan, K.M. Validity and reliability of the Purdue Pegboard Test in carpal tunnel syndrome. Muscle Nerve 2011, 43, 171-177. [CrossRef] [PubMed]

3. Desrosiers, J.; Hébert, R.; Bravo, G.; Dutil, E. The Purdue Pegboard Test: Normative data for people aged 60 and over. Disabil. Rehabil. 1995, 17, 217-224. [CrossRef] [PubMed]

4. İnal, E.E.; Çarlı, A.B.; Çanak, S.; Aksu, O.; Köroğlu, B.K.; Savaş, S. Effects of hyperthyroidism on hand grip strength and function. J. Rehabil. Res. Dev. 2015, 52, 663-668. [CrossRef] [PubMed]

5. Martins, M.; Neves, L.; Rodrigues, P.; Vasconcelos, O.; Castro, S.L. Orff-based music training enhances children's manual dexterity and bimanual coordination. Front. Psychol. 2018, 9, 2616. [CrossRef] [PubMed]

6. Servatius, R.J.; Spiegler, K.M.; Handy, J.D.; Pang, K.C.; Tsao, J.W.; Mazzola, C.A. Neurocognitive and fine motor deficits in asymptomatic adolescents during the subacute period after concussion. J. Neurotrauma 2018, 35, 1008-1014. [CrossRef] 
7. Lee, S.; Kim, Y.; Lee, B.H. Effect of virtual reality-based bilateral upper extremity training on upper extremity function after stroke: A randomized controlled clinical trial. Occup. Ther. Int. 2016, 23, 357-368. [CrossRef]

8. Martirosov, S.; Bureš, M.; Zítka, T. Cyber sickness in low-immersive, semi-immersive, and fully immersive virtual reality. Virtual Real. 2021, 1-18. [CrossRef]

9. Varley, B.J.; Shiner, C.T.; Johnson, L.; McNulty, P.A.; Thompson-Butel, A.G. Revisiting Poststroke Upper Limb Stratification: Resilience in a Larger Cohort. Neurorehabilit. Neural Repair 2021, 35, 280-289. [CrossRef] [PubMed]

10. Gaetani, F.; Primiceri, P.; Zappatore, G.A.; Visconti, P. Hardware design and software development of a motion control and driving system for transradial prosthesis based on a wireless myo-electric armband. IET Sci. Meas. Technol. 2019, 13, 354-362. [CrossRef]

11. Petracca, M.; Droby, A.; El Mendili, M.M.; Paduri, S.; Graziano, N.; Saba, N.; Falcone, A.; Kurz, D.; Riley, C.; Howard, J.; et al. Sociodemographic features and disability in african-american and caucasian patients with multiple sclerosis. Mult. Scler. J. 2020, 26, 197-198. [CrossRef]

12. Gogola, G.R.; Velleman, P.F.; Xu, S.; Morse, A.M.; Lacy, B.; Aaron, D. Hand dexterity in children: Administration and normative values of the functional dexterity test. J. Hand Surg. 2013, 38, 2426-2431. [CrossRef]

13. Lafayette Instrument Grooved Pegboard Test. Available online: https:/ /www.advys.be/docs/GroovedPegboardTestManual.pdf (accessed on 25 August 2021).

14. Hamilton, L.D.; Mazzo, M.R.; Petrigna, L.; Ahmed, A.A.; Enoka, R.M. Poor Estimates of Motor Variability Are Associated with Longer Grooved Pegboard Times for Middle-Aged and Older Adults. J. Neurophysiol. 2019, 121, 588-601. [CrossRef]

15. Petrigna, L.; Pajaujiene, S.; Iacona, G.M.; Thomas, E.; Paoli, A.; Bianco, A.; Palma, A. The Execution of the Grooved Pegboard Test in a Dual-Task Situation: A Pilot Study. Heliyon 2020, 6, e04678. [CrossRef] [PubMed]

16. Wang, Y.C.; Magasi, S.R.; Bohannon, R.W.; Reuben, D.B.; McCreath, H.E.; Bubela, D.J.; Gershon, R.C.; Rymer, W.Z. Assessing Dexterity Function: A Comparison of Two Alternatives for the NIH Toolbox. J. Hand Ther. 2011, 24, 313-321. [CrossRef]

17. Almuklass, A.M.; Capobianco, R.A.; Feeney, D.F.; Alvarez, E.; Enoka, R.M. Sensory Nerve Stimulation Causes an Immediate Improvement in Motor Function of Persons with Multiple Sclerosis: A Pilot Study. Mult. Scler. Relat. Disord. 2020, 38 , 101508. [CrossRef]

18. Agarwal, S.; Pawlak, N.; Cucca, A.; Sharma, K.; Dobbs, B.; Shaw, M.; Charvet, L.; Biagioni, M. Remotely-Supervised Transcranial Direct Current Stimulation Paired with Cognitive Training in Parkinson's Disease: An Open-Label Study. J. Clin. Neurosci. 2018, 57, 51-57. [CrossRef] [PubMed]

19. Mathiowetz, V.; Rogers, S.L.; Dowe-Keval, M.; Donahoe, L.; Rennells, C. The Purdue Pegboard: Norms for 14- to 19-Year-Olds. Am. J. Occup. Ther. 1986, 40, 174-179. [CrossRef] [PubMed]

20. Levine, A.J.; Miller, E.N.; Becker, J.T.; Selnes, O.A.; Cohen, B.A. Normative Data for Determining Significance of Test-Retest Differences on Eight Common Neuropsychological Instruments. Clin. Neuropsychol. 2004, 18, 373-384. [CrossRef]

21. Hyngstrom, A.S.; Cho, C.C.; Barillas, R.B.; Joshi, M.; Rowley, T.W.; Keenan, K.G.; Staudenmayer, J.; Swartz, A.M.; Strath, S.J. Identification of Latent Classes of Motor Performance in a Heterogenous Population of Adults. Arch. Rehabil. Res. Clin. Transl. 2020, 2, 100080. [CrossRef]

22. Waliño-Paniagua, C.N.; Gómez-Calero, C.; Jiménez-Trujillo, M.I.; Aguirre-Tejedor, L.; Bermejo-Franco, A.; Ortiz-Gutiérrez, R.M.; Cano-De-La-Cuerda, R. Effects of a Game-Based Virtual Reality Video Capture Training Program Plus Occupational Therapy on Manual Dexterity in Patients with Multiple Sclerosis: A Randomized Controlled Trial. J. Healthc. Eng. 2019, 9780587. [CrossRef] [PubMed]

23. Feys, P.; Lamers, I.; Francis, G.; Benedict, R.; Phillips, G.; Larocca, N.; Hudson, L.D.; Rudick, R. The Nine-Hole Peg Test as a Manual Dexterity Performance Measure for Multiple Sclerosis. Mult. Scler. 2017, 23, 711-720. [CrossRef] [PubMed]

24. Grice, K.O.; Vogel, K.A.; Le, V.; Mitchell, A.; Muniz, S.; Vollmer, M.A. Adult Norms for a Commercially Available Nine Hole Peg Test for Finger Dexterity. Am. J. Occup. Ther. 2003, 57, 570-573. [CrossRef] [PubMed]

25. Pavlova, E.L.; Borg, J. Impact of Tactile Sensation on Dexterity: A Cross-Sectional Study of Patients with Impaired Hand Function After Stroke. J. Mot. Behav. 2018, 50, 134-143. [CrossRef] [PubMed]

26. Jobbágy, Á.; Marik, A.R.; Fazekas, G. Quantification of the Upper Extremity Motor Functions of Stroke Patients Using a Smart Nine-Hole Peg Tester. J. Healthc. Eng. 2018, 7425858. [CrossRef]

27. Arduino-Mega-2560. Arduino Company. Available online: https://www.arduino.cc/en/Guide/ArduinoMega2560 (accessed on 30 June 2021).

28. Yang, L.; Zhang, F.; Zhu, J.; Fu, Y. A Portable Device for Hand Rehabilitation with Force Cognition: Design, Interaction and Experiment. IEEE Trans. Cogn. Dev. Syst. 2021. [CrossRef]

29. Pawar, S.S.; Chougule, S.R. Predication and Analysis of Epileptic Seizure Neurological Disorder Using Intracranial Electroencephalography (IEEG). WSEAS Trans. Signal Process. 2021, 16, 197-205. [CrossRef]

30. Davis Ojie, O.; Saatchi, R. Principal Component Analysis of the Modified Clinical Test Of sensory Interaction in Healthy Adult Humans. WSEAS Trans. Biol. Biomed. 2020, 17, 125-142. [CrossRef] 